\title{
Avances sobre el estudio de hígado graso en tilapias
}

\author{
Advances on the study of liver graso in tilapias
}

\author{
Avanços sobre o estudo de hígado graso em tilapias
}

Pedro A. Triana - García ${ }^{1 *}$; Mariana C. Gutiérrez - Espinosa $a^{2}$; Pedro R. Eslava-Mocha ${ }^{3 *}$

\author{
Estudiante MVZ; ${ }^{2} \mathrm{MVZ}, \mathrm{MSc} ;{ }^{3} \mathrm{MV}, \mathrm{MSc}$ \\ * Grupo de Sanidad de Organismos Acuáticos IALL UNILLANOS \\ ** Grupo IALL \\ Email: pedro.eslava@unillanos.edu.co
}

Recibido: septiembre 4 de 2012 Aceptado: noviembre 29 de 2012

\begin{abstract}
Resumen
Con el objeto de evaluar el efecto de dos fuentes de lípidos de origen animal y vegetal en el rendimiento productivo y la presentación de hígado graso en alevinos de tilapia hibrida (Oreochromisspp), se utilizaron seis dietas con aceite de pescado y aceite de soya como fuente de lípidos, con niveles de inclusión del 5\%, 9\% y 13\% de cada uno, durante un periodo de 60 días. Se determinaron parámetros de rendimiento productivo, índices corporales (índice hepatosomático-IHS, índice viscerosomático-IVS), glucosa sanguínea y triglicéridos séricos; adicionalmente se realizó evaluación histopatológica del hígado. Se observó un aumento significativo de peso $(\mathrm{p}<0.05)$ en los tratamientos con niveles de inclusión del $5 \%$, 9\% y $13 \%$ de aceite de soya respecto de los tratamientos con aceite de pescado con niveles de inclusión del $9 \%$ y $13 \%$. No se observaron diferencias significativas en la concentración de glucosa y triglicéridos. Con la fuente de lípidos de origen vegetal se observó una disminución significativa $(p<0.05)$ en el IHS para el tratamiento con un nivel de inclusión del $13 \%$, con respecto a los tratamientos con un nivel de inclusión del 5 y $9 \%$ de la fuente de lípidos de origen animal; el IVS no presento diferencias significativas entre tratamientos. La severidad de la infiltración grasa en el hígado fue menor en los tratamientos del $5 \%, 9 \%$ y $13 \%$ de aceite de soya, comparado con los tratamientos del 5\%, 9\% y 13\% de aceite de pescado. De acuerdo a los resultados observados, puede inferirse que el aceite de soya, rico en ácidos grasos poliinsaturados n-6, mejora el rendimiento productivo y disminuye la incidencia de lipidosis hepática en las tilapias hibridas cuando se compara con el aceite de pescado, fuente de lípidos ricas en ácidos grasos n-3 y poliinsaturados de cadena larga.
\end{abstract}

Palabras clave: Lipidosis hepática, degeneración grasa, hepatosis, Oreochromis nilotica.

Key words: Hepatic lipidosis, fatty degeneration, hepatosis, Oreochromis nilotica. 